\title{
Oral versus intramuscular cholecalciferol replacement in hemodialysis patients with vitamin $D$ deficiency
}

\author{
Maha A. Behairy ${ }^{1 *}$, Reem M. Elsharabasy ${ }^{1}$, Abdel Bassit El Shaarawy ${ }^{1}$, Walid Anwar ${ }^{1}$, Zeinab Ahmed \\ Mahmoud $^{2}$, Lina Essam Khedr ${ }^{1}$ \\ ${ }^{1}$ Department of Internal Medicine and Nephrology, Faculty of Medicine, Ain Shams University, Cairo, Egypt \\ ${ }^{2}$ El-Helal Medical Insurance Hospital, Cairo, Egypt
}

\section{AR T I C L E I N F O}

Article Type:

Original

\section{Article History:}

Received: 20 Jnauary 2021

Accepted: 17 May 2021

Published online: 19 June 2021

\section{Keywords:}

Cholecalciferol

Hemodialysis

$25 \mathrm{OH}$ vitamin $\mathrm{D}$

Hyperparathyroidism

\begin{abstract}
A B S T R A C T
Introduction: Low 25-hydroxyvitamin D (25(OH)D) level in hemodialysis (HD) patients is associated with high bone turnover, secondary hyperparathyroidism, and decreased bone mineral density (BMD).

Objective: To investigate the efficacy of equivalent doses of pulse oral cholecalciferol versus intramuscular (IM) cholecalciferol in correcting serum $25(\mathrm{OH}) \mathrm{D}$ levels in HD patients with vitamin $\mathrm{D}$ deficiency.

Patients and Methods: In a prospective randomized open-label clinical trial, $80 \mathrm{HD}$ patients with $25(\mathrm{OH}) \mathrm{D}$ level $<20 \mathrm{ng} / \mathrm{mL}$ and serum intact parathyroid hormone (iPTH) level $>100 \mathrm{pg} / \mathrm{mL}$ were enrolled in the study. Patients were divided into two groups. Group I: $40 \mathrm{HD}$ patients received oral cholecalciferol 25000 IU weekly for 12 weeks. Group II: $40 \mathrm{HD}$ patients received a single dose of IM cholecalciferol 300000 IU. Patients were maintained on their regular medications as alfacalcidol or phosphate binders. Serum calcium, phosphorus, $25(\mathrm{OH}) \mathrm{D}$, alkaline phosphatase and $\mathrm{iPTH}$ were monitored at $0,6^{\text {th }}$, and $12^{\text {th }}$ week of intervention.

Results: Significant increase in serum $25(\mathrm{OH}) \mathrm{D}$ level in group II patients who received IM (intramuscular) cholecalciferol, with delta mean a change of vitamin D level was $2.92 \pm 7.29 \mathrm{ng} / \mathrm{mL}$ over three months in comparison to the insignificant change in oral cholecalciferol group. Additionally there was a significant increase in the mean of serum calcium in comparison to oral cholecalciferol group, while we found a statistically significant decrease in alkaline phosphatase level in both groups too $(P<0.05)$. The mean of iPTH levels was reduced significantly with IM cholecalciferol dose $(1064.00 \pm 787.60$ to $609.9 \pm 551.41 \mathrm{pg} / \mathrm{mL} ; P<0.05)$.

Conclusion: Intramuscular cholecalciferol dose is more effective at increasing $25(\mathrm{OH}) \mathrm{D}$ levels in dialysis patients than oral supplementation, achieves more increase in serum calcium and reduce $\mathrm{iPTH}$ levels. However, the longer duration of treatment is required to achieve recommended levels of vitamin D and suppress high iPTH levels.
\end{abstract}

Implication for health policy/practice/research/medical education:

Low $25(\mathrm{OH})$ D serum levels is prevalent condition among end-stage renal disease patients on regular hemodialysis associated with increased risk of decreased BMD, risk of bone fractures and increased cardiovascular morbidity. There are various clinical regimens with several forms of vitamin D supplementations among hemodialysis patients with variable outcomes in clinical practice. Cholecalciferol form is apparently cost-effective and safe drug that can be used to correct $25(\mathrm{OH}) \mathrm{D}$ serum level without evident toxicity. This study evaluates the short-term effect of intramuscular cholecalciferol replacement versus weekly oral supplementation on serum vitamin D level and biochemical parameters of bone metabolism in hemodialysis patients with vitamin D deficiency..

Please cite this paper as: Behairy MA, Elsharabasy RM, El Shaarawy AB, Anwar W, Mahmoud ZA, Khedr LE. Oral versus intramuscular cholecalciferol replacement in hemodialysis patients with vitamin D deficiency. J Nephropharmacol. 2022;11(1):e07. DOI: $10.34172 /$ npj.2022.07.

\section{Introduction}

Vitamin D a pro-hormone which exists in two major forms of vitamin D, ergocalciferol (vitamin D2) and cholecalciferol (vitamin $\mathrm{D}_{3}$ ) (1). Approximately $90 \%$ of total body vitamin $\mathrm{D}$ is synthesized endogenously and the rest is ingested orally, 7 dehydroxycholesterol (provitamin D) in the skin when exposed to ultraviolet light transforms to pre-vitamin $\mathrm{D}$ which transforms spontaneously to 
cholecalciferol (vitamin D3) (2). It is hydroxylsed then in the liver to 25-hydroxy vitamin $\mathrm{D}$ and the second hydroxylation in the kidneys to 1,25 hydroxy vitamin $\mathrm{D}$. Recent studies have shown that several tissues, other than the kidneys, express the enzyme CYP27B1, responsible for the 1-hydroxylation of 25(OH)D (3). Thus, activation of vitamin $\mathrm{D}$ occurs in several extrarenal cells and may be associated with significant biological roles beyond those traditionally attributed to vitamin D (4). There has been a great deal of interest in the study of those other biological roles of vitamin $\mathrm{D}$ during the past few years, several studies have shown that $25(\mathrm{OH}) \mathrm{D}$ deficiency is associated with increased risk of cardiovascular, musculoskeletal and autoimmune diseases, cancer, infections, diabetes, and mortality (5-7).

Vitamin D deficiency is defined as a serum $25(\mathrm{OH}) \mathrm{D}$ level $<20 \mathrm{ng} / \mathrm{mL}$ and insufficiency as between 21 and 29 $\mathrm{ng} / \mathrm{mL}$; a target of $>30 \mathrm{ng} / \mathrm{mL}$ is suggested for the general population $(4,5)$. Studies have shown a high-prevalence of vitamin $\mathrm{D}$ deficiency and insufficiency in chronic kidney disease (CKD) patients sometimes reaching over $80 \%(8)$. Causes of $25(\mathrm{OH}) \mathrm{D}$ deficiency in dialysis and CKD population include deficient sunlight exposure (9) and the fact that CKD patients frequently have a poor diet due to numerous reasons such as reduced appetite, uremic-related gastrointestinal symptoms and dietary restrictions (10). Vaziri et al in an experimental study showed that uremic rats had a significantly decreased rate of jejunal absorption of vitamin $\mathrm{D}_{3}$ compared to control animals (11), suggesting that uremia leads to impaired oral absorption of vitamin D3.

Vitamin D deficiency has been implicated in several health adverse effects. It is associated with increased risk and severity of infection (12), and impaired cardiac contractility $(13,14)$. Moreover it has been associated with muscular weakness, increased risk of falls (15) and vascular calcifications in dialysis patients (16). Recent guidelines recommend giving oral vitamin $\mathrm{D}$ supplementation to patients on maintenance hemodialysis (HD) who have low serum levels (17). The appropriate treatment strategy for vitamin $\mathrm{D}$ deficiency in dialysis treatment is controversial. Cholecalciferol versus ergocalciferol supplementation, oral versus intramuscular (IM) administration, fixed dosing versus titrated dosing strategy, lower daily dose or higher intermittent dose. Besides, there still is some debate concerning the target concentrations to be achieved, serum concentration ranging from $75-150 \mathrm{nmol} / \mathrm{L}$ is considered to provide the optimal health benefit with minimal adverse effects $(4,5)$. The dose of cholecalciferol needed to reach this level varies widely, discrepancies can be partially related to differences in the bioavailability of the large variety of vitamin D compounds found throughout the world $(3,18)$.

Few data exist about the accuracy of the available automated immunoassays for $25(\mathrm{OH}) \mathrm{D}$ determinations, particularly in patients on dialysis $(19,20)$ whether levels are over or underestimated is not known. The most recent KDIGO guidelines suggest using "treatment strategies recommended for the general population" (21). Because of debate concerning about the correction of vitamin D level $25(\mathrm{OH}) \mathrm{D}$ cautiously without increased the incidence of hyperphosphatemia or hypercalcemia among HD patients,

\section{Objectives}

We aimed to test the short-term effect of equivalent doses of pulse oral cholecalciferol (25000 IU weekly for 12 weeks) versus single IM cholecalciferol (300000 IU) in correcting serum $25(\mathrm{OH})$ D levels in HD patients and its effects on biochemical parameters of bone metabolism as a pilot study.

\section{Patients and Methods}

This is a prospective randomized open-label clinical trial over 12 weeks duration, 80 end-stage renal disease patients (ESRD) on conventional HD were recruited from El-Helal Medical Insurance Hospital and Ain Shams university hospital, Egypt, were enrolled in the study. Eligibility criteria were; Adult patients $\geq 18$-year-old on regular HD thrice weekly for more than 6 months using low flux dialyzers, standard bicarbonate dialysate and conventional heparin anticoagulation, with dialysate calcium concentration was $1.5 \mathrm{mmol}$, patients with vitamin D deficiency (serum 25(OH)D) level $<20 \mathrm{ng} / \mathrm{mL}$ ) and serum intact parathyroid hormone (iPTH) level $>100$ $\mathrm{pg} / \mathrm{mL}$. Patients with hypercalcemia (serum calcium $>$ $10.5 \mathrm{mg} / \mathrm{dL})$, calcium phosphorous product $\left(\mathrm{Ca} \times \mathrm{P} \mathrm{mg}^{2} /\right.$ $\left.\mathrm{dL}^{2}\right) \geq 55$, patients with an evident history of intestinal malabsorption, chronic diarrhoea or sarcoidosis, malignancy or decompensated liver disease all were excluded from the study. Patients with a history of intake of cholecalciferol or ergocalciferol 6 months before the study or current use of any medication that could influence vitamin D metabolism such as (phenytoin, phenobarbital or rifampicin), or hypersensitivity to vitamin D3 drug were also excluded from this study.

The eligible prevalent HD patients with vitamin D deficiency were randomized by the odd method to two groups (A, B). Both groups received equivalent doses of cholecalciferol. Group A; $40 \mathrm{HD}$ patients received oral cholecalciferol $25000 \mathrm{IU}$ (9 mL) weekly for 12 weeks. Oral cholecalciferol (Vidrop ${ }^{\circledR} 2800 \mathrm{IU} / \mathrm{mL}$ ) manufactured by medical union pharmaceuticals). Patients were advised to take oral cholecalciferol post HD session in the trial to increase compliance. Group B; $40 \mathrm{HD}$ patients received a single IM injection (IM) of cholecalciferol 300000 IU, (Devarol $® 200000$ IU/ampoule) manufactured by Chemipharm Pharmaceutical Industries), IM of cholecalciferol was given in day other than a day of HD session. The primary outcome was increased level of 
25(OH)D up to $30 \mathrm{ng} / \mathrm{mL}$. Secondary outcomes; effect on calcium, phosphorous, calcium phosphorous product, intact PTH level and CRP titre. Vitamin D supplements were stopped if serum calcium $>10.5 \mathrm{mg} / \mathrm{dL}$ or $25(\mathrm{OH}) \mathrm{D}$ level $>100 \mathrm{ng} / \mathrm{mL}$ (toxic level) during study. Both groups were maintained on their regular medications used to control mineral bone disorder as alfacalcidol, sevelamer or a calcium-based chelator. All patients were subjected to full history and physical examination with emphasis on demographic data age, gender, duration of $\mathrm{HD}$, cause of renal failure, history of fractures or fall, comorbidities, and medications. Laboratory tests included (serum calcium, phosphorus, $25(\mathrm{OH}) \mathrm{D}$, alkaline phosphatase (ALP) and iPTH, hemoglobin, ferritin, CRP titre and urea reduction ratio (URR). Serum 25(OH)vitamin D level was measured by ELISA (Calbiotech, USA, REF: VD2208). Serum samples were collected and centrifuged and separated as soon as possible, stored at $-20^{\circ} \mathrm{C}$. All specimens were allowed to come to room temperature before use. Tests were assessed at baseline, 6th week and 12th week of the study.

\section{Statistical analysis}

Analysis of data was conducted using SPSS program version 23 quantitative data were presented as mean and SD qualitative data were presented as count and percentage. Student $t$ test was used to compare quantitative data between two independent groups and Mann-Whitney $U$ test was used for non-parametric data. Chi-square test was used for comparison of qualitative data. Paired samples $t$ test, Wilcoxon signed-rank and repeated measure ANOVA test were used for comparison of quantitative data at different time points for the same group. $P$ value $<0.05$ was considered statistically significant. Mean delta change $(\Delta)$ of vitamin $\mathrm{D}$ level was calculated $=(12 \mathrm{~W}$ serum level-baseline level).

\section{Results}

Eighty patients on regular HD with vitamin D deficiency, 4 patients were lost in the follow up, 76 patients were complete the study (29 [38.15\%] females and 47 [61.84\%] males) with mean age $50.53 \pm 15.32$ years; the mean of time on dialysis was $5.82 \pm 3.77$ years (Figure 1). The enrolled patients were maintained on their regular medications used to control bone mineral density (BMD) before the intervention, $29(80.6 \%)$ of the patients used phosphate binders (sevelamer or calcium-based phosphate binders), $20(55.6 \%)$ of the patients used alfacalcidol and $3(8.3 \%)$ patients used cinacalcet. Eighteen $(50 \%)$ of the patients had symptoms of vitamin D deficiency and BMD as muscle pain or weakness and $5(13.9 \%)$ of patients had an evident history of bone fractures before the start of the study. The patients were randomly divided into two groups, $37 \mathrm{HD}$ patients were in group I and $39 \mathrm{HD}$ patients in group II. There were no statistically significant differences as regards baseline demographic, clinical data and laboratory results between the studied patients groups $\mathrm{A}$ and $\mathrm{B}$ as illustrated in (Tables 1 and 2).

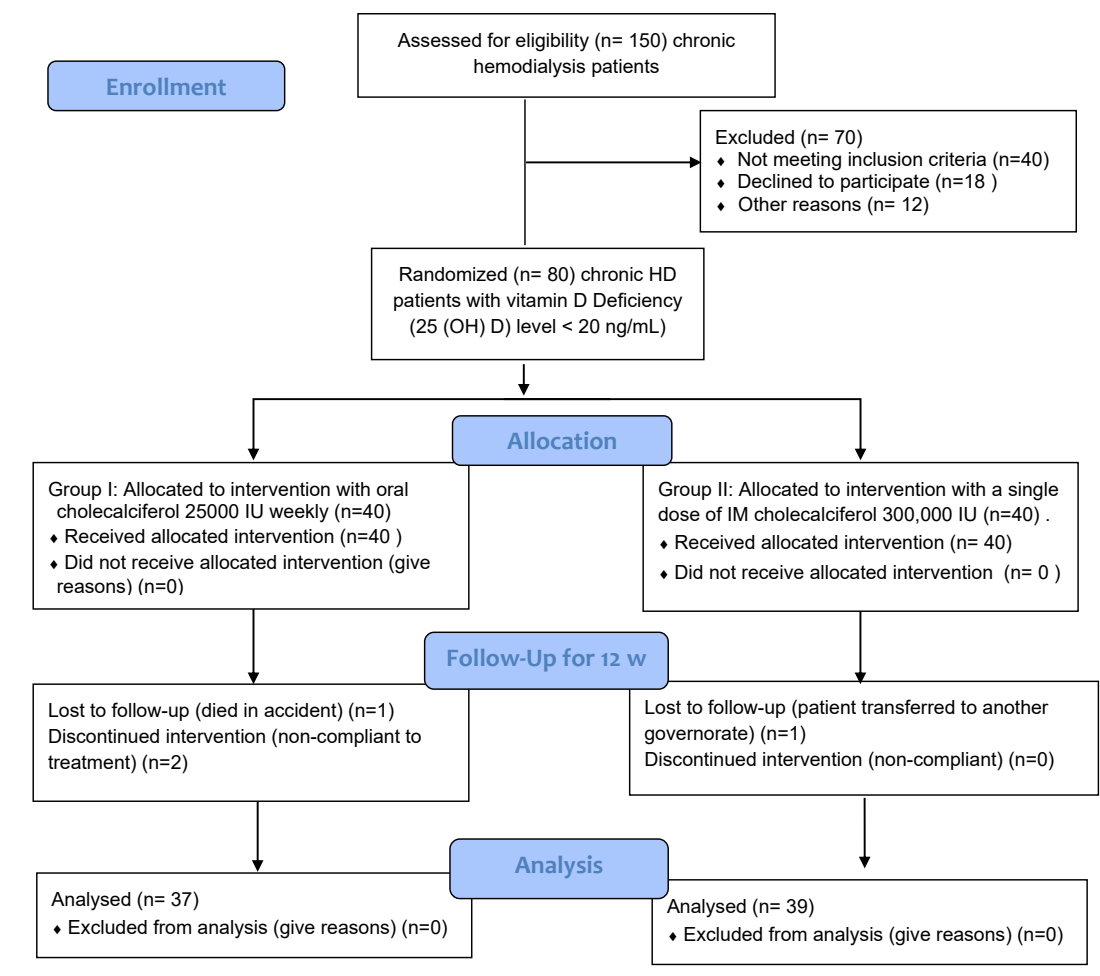

Figure 1. CONSORT Flow diagram of the study. 
In group A (oral cholecalciferol group), there was significant decrease not increase in vitamin D level, with statistical significant decrease in alkaline phosphatase and statistical significant increase $\mathrm{Ca} \times \mathrm{P}$ product $(P<0.05)$. Additionally, there were no statistically significant changes in $\mathrm{Ca}$, phosphorus and a non-significant decrease in PTH levels over the 12 weeks of the study as shown in Table 3.

In group B patients (IM cholecalciferol), there was a statistically significant increase in the vitamin $\mathrm{D}$ level $(10.54 \pm 5.14$ to $13.45 \pm 5.72 \mathrm{ng} / \mathrm{mL})$ with $\Delta$ mean of change of vitamin D level $=2.92 \pm 7.29 \mathrm{ng} / \mathrm{mL}$ at the end of 12 weeks of the study. We also found a statistical significant increase in serum Ca level, a significant decrease in alkaline phosphatase level and an increase in Ca $\times$ P. Additionally, a significant reduction $\mathrm{PTH}$ level $(1064.00 \pm 787.60$ to $609.9 \pm 551.41 \mathrm{pg} / \mathrm{mL})(P<0.05)$ and no significant hyperphosphatemia as shown (Table 4).

As regards the comparison between the studied groups there was a statistically significant difference between two groups in vitamin D level after 12 weeks of intervention $(P$ value $=0.03)($ Table 5$)$. Significant increase in vitamin $\mathrm{D}$ level over time among studied groups was shown in Figure 2 with better response in the group with IM supplementation. Repeated measure ANOVA test revealed for vitamin D level, that there was significant "withinsubjects" effect indicating a significant change in vitamin $\mathrm{D}$ level over time $(\mathrm{F}=6.60, P=0.002)$. However, there were no significant differences between the two studied groups regarding changes of alkaline phosphatase levels $(\mathrm{F}=0.32$, $P=0.58)$ or $\mathrm{Ca} \times \mathrm{P}(\mathrm{F}=0.02, P=0.90)(P>0.05)$.

There was a decrease in the CRP titer by vitamin $D$ supplementation in both studied groups but insignificant change statistically. Four patients in group A and three patients in group B were improved regarding muscle pain and weakness after treatment with no significant difference between the two groups.

\section{Discussion}

In this prospective randomized interventional study compared IM cholecalciferol versus weekly oral doses of cholecalciferol effect on vitamin $\mathrm{D}$ and biochemical parameters of bone minerals metabolism. It was evident that both groups have failed to reach target vitamin $\mathrm{D}$ levels after 12 weeks of treatment. In a study involving 64 HD patients using a regimen of 20000 IU cholecalciferol per week, Tokmak et al found that $25 \mathrm{OH}$ vitamin $\mathrm{D}$ levels

Table 1. The baseline demographic and clinical data of the studied patients' groups

\begin{tabular}{|c|c|c|c|c|c|c|}
\hline & \multicolumn{2}{|c|}{$\begin{array}{c}\text { A group } \\
\text { Oral cholecalciferol }(n=37)\end{array}$} & \multicolumn{2}{|c|}{$\begin{array}{c}\text { B group } \\
\text { IM cholecalciferol }(n=39)\end{array}$} & \multirow[t]{2}{*}{ Statistical test } & \multirow[t]{2}{*}{$P$ value } \\
\hline & Mean & SD & Mean & SD & & \\
\hline \multirow[t]{2}{*}{ Age } & 45 & 16 & 53 & 13 & $2.00^{\mathrm{a}}$ & 0.06 \\
\hline & $\mathbf{N}$ & $\%$ & $\mathbf{N}$ & $\%$ & & \\
\hline \multicolumn{7}{|l|}{ Gender } \\
\hline Female & 15 & $40.5 \%$ & 14 & $35.85 \%$ & \multirow{2}{*}{$0.36^{b}$} & \multirow{2}{*}{0.55} \\
\hline \multirow[t]{2}{*}{ Male } & 22 & $59.4 \%$ & 25 & $64.1 \%$ & & \\
\hline & Mean & SD & Mean & SD & & \\
\hline Dry weight (kg) & 69.21 & 17.52 & 77.13 & 13.57 & $1.53^{a}$ & 0.14 \\
\hline $\mathrm{BMI}\left(\mathrm{kg} / \mathrm{m}^{2}\right)$ & 25.12 & 5.38 & 26.37 & 4.16 & $0.78^{a}$ & 0.44 \\
\hline \multirow[t]{2}{*}{ Dialysis duration (y) } & 5.76 & 2.97 & 5.87 & 4.44 & $0.08^{a}$ & 0.94 \\
\hline & $\mathbf{N}$ & $\%$ & $\mathbf{N}$ & $\%$ & & \\
\hline \multicolumn{7}{|c|}{ Causes of renal disease } \\
\hline Diabetes mellitus & 2 & $11.8 \%$ & 3 & $15.8 \%$ & \multirow{4}{*}{$1.17^{c}$} & \multirow{4}{*}{0.83} \\
\hline Hypertension & 5 & $29.4 \%$ & 3 & $15.8 \%$ & & \\
\hline Polycystic kidney & 2 & $11.8 \%$ & 3 & $15.8 \%$ & & \\
\hline Other causes & 8 & $47.1 \%$ & 10 & $52.6 \%$ & & \\
\hline \multicolumn{7}{|l|}{ Muscle pain } \\
\hline Yes & 11 & $64.7 \%$ & 7 & $36.8 \%$ & \multirow{2}{*}{$2.79^{b}$} & \multirow{2}{*}{0.10} \\
\hline No & 6 & $35.3 \%$ & 12 & $63.2 \%$ & & \\
\hline \multicolumn{7}{|c|}{ History of bone fracture } \\
\hline Yes & 2 & $11.8 \%$ & 3 & $15.8 \%$ & \multirow[t]{2}{*}{$0.12^{c}$} & \multirow{2}{*}{1.00} \\
\hline No & 15 & $88.2 \%$ & 16 & $84.2 \%$ & & \\
\hline \multicolumn{7}{|l|}{ Drug history } \\
\hline \multicolumn{7}{|l|}{ Phosphate binders } \\
\hline Yes & 15 & $88.2 \%$ & 14 & $73.7 \%$ & \multirow[t]{2}{*}{$1.21^{c}$} & \multirow{2}{*}{0.41} \\
\hline No & 2 & $11.8 \%$ & 5 & $26.3 \%$ & & \\
\hline \multicolumn{7}{|l|}{ Alfacalcidol } \\
\hline Yes & 9 & $52.9 \%$ & 11 & $57.9 \%$ & \multirow{2}{*}{$0.09^{b}$} & \multirow{2}{*}{0.77} \\
\hline No & 8 & $47.1 \%$ & 8 & $42.1 \%$ & & \\
\hline
\end{tabular}

a Student $t$ test; ${ }^{\mathrm{b}}$ Chi square test; ${ }^{\mathrm{c}}$ Fisher Exact test. 
Table 2. Comparison between the studied groups regarding baseline laboratory investigation

\begin{tabular}{|c|c|c|c|c|c|c|}
\hline & \multicolumn{2}{|c|}{ Oral cholecalciferol group $(n=37)$} & \multicolumn{2}{|c|}{ IM cholecalciferol group $(n=39)$} & \multirow{2}{*}{$t^{*}$} & \multirow{2}{*}{$P$ value } \\
\hline & Mean & SD & Mean & SD & & \\
\hline Vitamin D (25(OH) D) level (ng/mL) & 11.91 & 6.13 & 10.54 & 5.14 & 0.73 & 0.47 \\
\hline Calcium level (mg/dL) & 8.37 & 0.70 & 8.19 & 0.69 & 0.78 & 0.44 \\
\hline Phosphorus level (mg/dL) & 4.68 & 0.96 & 4.84 & 1.14 & 0.47 & 0.64 \\
\hline Ca $\times$ P products & 39.07 & 8.29 & 39.28 & 9.06 & 0.07 & 0.94 \\
\hline $\operatorname{ALP}(\mathrm{U} / \mathrm{L})$ & 217.17 & 179.6 & 252.21 & 213.03 & 0.56 & 0.58 \\
\hline PTH level $(\rho g / m L)$ & 889.84 & 533.02 & 1064.0 & 787.5 & 0.76 & 0.448 \\
\hline Hemoglobin level (g/dL) & 10.56 & 1.61 & 10.44 & 1.88 & 0.20 & 0.84 \\
\hline Serum creatinine $(\mathrm{mg} / \mathrm{dL})$ & 7.49 & 2.43 & 10.43 & 2.44 & 3.61 & 0.001 \\
\hline $\mathrm{CRP}(\mathrm{mg} / \mathrm{L})$ & 10.76 & 24.77 & 9.84 & 22.88 & $0.28 * *$ & 0.83 \\
\hline URR (\%) & 63.30 & 9.06 & 64.01 & 9.50 & 2.67 & 0.54 \\
\hline $\mathrm{Kt} / \mathrm{V}$ & 1.841 & 0.466 & 1.416 & 0.287 & 4.12 & 0.06 \\
\hline
\end{tabular}

*Student $\mathrm{t}$ test, ** Mann Whitney U test.

Table 3. Lab investigations before and after treatment in group A (Oral cholecalciferol)

\begin{tabular}{|c|c|c|c|c|}
\hline & Mean & SD & Test value & $P$ value \\
\hline Vitamin D level baseline & $11.91^{\mathrm{a}}$ & 6.13 & \multirow{3}{*}{$4.09 *$} & \multirow{3}{*}{0.03} \\
\hline Vitamin D level 6 weeks & $6.86^{\mathrm{b}}$ & 4.51 & & \\
\hline Vitamin D level 12 weeks & 9.30 & 5.29 & & \\
\hline Ca baseline & 8.37 & 0.70 & \multirow{3}{*}{$0.56^{*}$} & \multirow{3}{*}{0.58} \\
\hline Ca 6 weeks & 8.21 & 0.96 & & \\
\hline Ca 12 weeks & 8.41 & 1.01 & & \\
\hline Phosphorus baseline & 4.68 & 0.96 & \multirow{3}{*}{$3.30 *$} & \multirow{3}{*}{0.06} \\
\hline Phosphorus 6 weeks & 4.95 & 1.10 & & \\
\hline Phosphorus 12 weeks & 5.36 & 1.03 & & \\
\hline $\mathrm{Ca} \times \mathrm{P}$ product baseline & $39.07^{a}$ & 8.29 & \multirow{3}{*}{$5.46^{*}$} & \multirow{3}{*}{0.01} \\
\hline Ca $\times$ P product 6 weeks & $40.50^{\mathrm{a}}$ & 9.33 & & \\
\hline Ca $\times$ P product 12 weeks & $45.10^{b}$ & 10.03 & & \\
\hline ALP baseline & 217.18 & 179.60 & \multirow{2}{*}{$2.33^{* *}$} & \multirow{2}{*}{0.03} \\
\hline ALP 12 weeks & 151.77 & 104.17 & & \\
\hline PTH baseline & 889.84 & 533.02 & \multirow{2}{*}{$1.73 * *$} & \multirow{2}{*}{0.10} \\
\hline PTH 12 weeks & 697.99 & 460.9 & & \\
\hline CRP baseline & 10.76 & 24.77 & \multirow{2}{*}{$1.84 * * *$} & \multirow{2}{*}{0.07} \\
\hline CRP 12 weeks & 2.12 & 5.53 & & \\
\hline
\end{tabular}

*Repeated measure ANOVA test (a,b post hoc test), **Paired samples $t$ test, *** Wilcoxon signed-rank test.

increased ( 17.5 to $80 \mathrm{nmol} / \mathrm{L}$ ) in 9 months with over $57 \%$ of patients reaching the K/DOQI recommended level of vitamin D (22). Monthly dosing of 100000 IU oral cholecalciferol was used by Jean et al in a study involving 107 HD patients, after 15 months of treatment vitamin D levels increased from (32 to $105 \mathrm{nmol} / \mathrm{L}$ ) with most patients reaching plateau levels by 9 months (23). In our study, failure to achieve target levels of vitamin D in the oral group can be related to shorter duration of treatment (12 weeks versus 9 months) and possibly poor absorption of vitamin D oral formulation. This condition was avoided in the IM group who received a single IM injection of $300000 \mathrm{IU}$ cholecalciferol and even though target vitamin D levels were not reached. Furthermore possibly because of the short duration of treatment, a significant increase in vitamin $\mathrm{D}$ level from baseline as delta means of change $(2.92 \pm 7.29 \mathrm{ng} / \mathrm{mL})$ was observed showing evidence that IM high dose cholecalciferol was superior to oral treatment and has elevated levels of vitamin $\mathrm{D}$ in a shorter time frame. In a study by Descombes et al the required doses of the oral post-dialysis cholecalciferol supplement needed to maintain the $25(\mathrm{OH}) \mathrm{D}$ levels within the target levels varied widely, more than one-third of patients required cholecalciferol supplementation of (4000 or $2000 \mathrm{IU} /$ week) to achieve vitamin D repletion, nearly one-third required much higher doses, up to 12000 IU/week ( $\approx 50000 \mathrm{IU} /$ month) (24). This variability in the response detects that patients with advanced CKD stages may have individual differences in the metabolism of vitamin $\mathrm{D}$, which leads to different response to vitamin D supplementation. Previous researches have shown that using fixed doses of vitamin $\mathrm{D}$ in patients who have lower 
Table 4. Lab investigations before and after treatment in group B (IM cholecalciferol)

\begin{tabular}{|c|c|c|c|c|}
\hline & Mean & SD & Test value & $P$ value \\
\hline Vitamin D level baseline & 10.54 & 5.14 & \multirow{3}{*}{$6.03 *$} & \multirow{3}{*}{0.01} \\
\hline Vitamin D level 6 weeks & $8.86^{a}$ & 4.64 & & \\
\hline Vitamin D level 12 weeks & $13.45^{\mathrm{b}}$ & 5.72 & & \\
\hline Ca baseline & 8.19 & 0.69 & \multirow{3}{*}{$7.02 *$} & \multirow{3}{*}{0.003} \\
\hline Ca 6 weeks & $8.01^{\mathrm{a}}$ & 0.65 & & \\
\hline Ca 12 weeks & $8.42^{b}$ & 0.54 & & \\
\hline Phosphorus baseline & 4.84 & 1.14 & \multirow{3}{*}{$3.002^{*}$} & \multirow{3}{*}{0.06} \\
\hline Phosphorus 6 weeks & 5.42 & 1.60 & & \\
\hline Phosphorus 12 weeks & 5.20 & 1.44 & & \\
\hline Ca $\times$ P product baseline & $39.28^{\mathrm{a}}$ & 9.06 & \multirow{3}{*}{$4.02 *$} & \multirow{3}{*}{0.03} \\
\hline $\mathrm{Ca} \times \mathrm{P}$ product 6 weeks & 43.11 & 11.68 & & \\
\hline $\mathrm{Ca} \times \mathrm{P}$ product 12 weeks & $43.49^{b}$ & 11.33 & & \\
\hline ALP baseline & 184.58 & 222.80 & \multirow{2}{*}{$2.71^{* *}$} & \multirow{2}{*}{0.01} \\
\hline ALP 12 weeks & 252.21 & 213.04 & & \\
\hline PTH baseline & 1064.00 & 787.60 & \multirow{2}{*}{$4.47^{* *}$} & \multirow{2}{*}{$<0.001$} \\
\hline PTH 12 weeks & 609.9 & 551.41 & & \\
\hline CRP baseline & 9.84 & 22.88 & \multirow{2}{*}{$1.01^{* * *}$} & \multirow{2}{*}{0.07} \\
\hline CRP 12 weeks & 6.26 & 15.00 & & \\
\hline
\end{tabular}

*Repeated measure ANOVA test (a,b post hoc test), **Paired samples $t$ test, *** Wilcoxon signed-rank test.

Table 5. Comparison between two study groups regarding serum vitamin $D(25(\mathrm{OH}) \mathrm{D})$ level after treatment

\begin{tabular}{|c|c|c|c|c|c|c|}
\hline & \multicolumn{2}{|c|}{ Oral cholecalciferol group $(n=37)$} & \multicolumn{2}{|c|}{ IM cholecalciferol group $(n=39)$} & \multirow{2}{*}{ Test value* } & \multirow{2}{*}{$P$ value } \\
\hline & Mean & SD & Mean & SD & & \\
\hline Vitamin D level baseline & 11.91 & 6.13 & 10.54 & 5.14 & 0.73 & 0.47 \\
\hline Vitamin D level 6 weeks & 6.86 & 4.51 & 8.86 & 4.64 & 1.31 & 0.20 \\
\hline Vitamin D level 12 weeks & 9.30 & 5.29 & 13.45 & 5.72 & 2.25 & 0.03 \\
\hline
\end{tabular}

*Student $t$ test .

baseline levels results in lower steady-state concentrations under supplementation and requires higher doses of vitamin $\mathrm{D}$ for increase the patient serum $25(\mathrm{OH}) \mathrm{D}$ levels than those patients with higher baseline levels of vitamin D $(3,18,25)$.

Compliance to treatment was ensured in our study by receiving supplementation post dialysis, a single IM dose

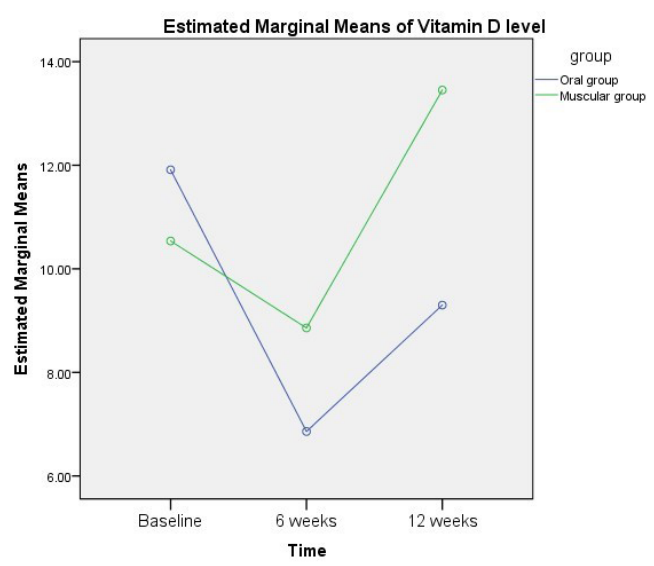

Figure 2. The change of serum $25(\mathrm{OH}) \mathrm{D}$ levels among Hemodialysis patients received oral cholecalciferol versus patients received IM cholecalciferol. might have to be repeated every three months to ensure optimum results but might show more compliance than oral dosing in the condition where treatment might continue for longer duration making it more likely to miss oral doses. This is usually not the case for daily prescriptions, which, according to the literature, are associated with a compliance rate that generally does not exceed $70 \%$ (24). However, a recent meta-analysis of randomized controlled trials has shown that daily (or weekly) vitamin $\mathrm{D}_{3}$ doses are more efficient to reduce acute respiratory tract infections than monthly doses (26). Furthermore, a randomized controlled trial published in 2010 observed that elderly women who received an annual dose of 500,000 IU of vitamin D had more falls than those who received the placebo (27). Recently, Bischoff-Ferrari et al have shown in an RCT that frail elderly patients who received monthly doses of 60,000 IU during one year sustained significantly more falls than other patients who were randomized to 24,000 IU per month, even though the group who received higher doses were more likely to reach recommended levels of vitamin D (28).

In our study, we observed an increase in calcium levels in group B $(8.19 \mathrm{~g} / \mathrm{dL}$ to $8.42 \mathrm{~g} / \mathrm{dL} ; P=0.003)$, while levels of calcium in group A were stable, however this increase in serum calcium may be partly attributed to the fact that 
patients on alfacalcidol were not excluded and to the fact that those patients who received IM injections achieved a more significant increase in their vitamin D levels. Phosphate levels were steady in both treatment groups; however, phosphate binders were taken by 20 patients in our study. Prior studies reported that supplementation with ergocalciferol or cholecalciferol has no significant effects on the phosphate levels and may be associated with hypercalcemia in only $3 \%$ of the patients (29). In a study mentioned earlier by Descombes et al, mild transient episodes of hypercalcemia occurred in 3 patients who were receiving calcitriol with vitamin D3 (24). This supports the data reported by Heaney et al, which showed that calcium levels are influenced by low-doses of calcitriol but not by cholecalciferol supplementation unless doses over $50000 \mathrm{IU} /$ day are given (30).

Several studies have shown a decline in iPTH levels post vitamin D supplementation. In a study in 2008 conducted over 253 dialysis patients, all patients receiving daily oral cholecalciferol for 6 months have shown a decrease in iPTH level $(235 \pm 186$ to $189 \pm 137 \mathrm{pg} / \mathrm{mL})$ except patients who showed a suboptimal response to vitamin D supplementation (those who achieved vitamin D levels $<75 \mathrm{nmol} / \mathrm{L})(31)$, those patients did not exhibit the same iPTH decrease as other patients in the study. In the present study, the IM cholecalciferol supplementation had an inhibitory effect on secondary hyperparathyroidism and no suppression effect by the oral IM cholecalciferol supplementation. This provides further evidence that treatment with vitamin D either oral or IM should continue till reaching 25(OH)D targets levels to have an inhibitory effect on hyperparathyroidism. A recent randomized controlled trial evaluating short-term effects of weekly or monthly doses of ergocalciferol supplementation failed to find a significant effect on iPTH level (32). However, several studies doubt the efficacy of ergocalciferol in vitamin D supplementation as it was observed that ergocalciferol was less potent than cholecalciferol in achieving $25(\mathrm{OH})$ $\mathrm{D}$ targets(33). This could be due to a stronger affinity of cholecalciferol to the vitamin D binding protein (34).

It is to be noted that a number of our patients had elevated iPTH over $600 \mathrm{pg} / \mathrm{mL}$, elevation in iPTH in some patients in our study suggest that maybe further specific treatment in the form of cinacalcet or activated vitamin $\mathrm{D}$ were needed to inhibit the pathological mechanism causing hyperparathyroidism and that cholecalciferol is not sufficient alone to cause suppression in PTH at these levels.

\section{Conclusion}

IM supplementation is more effective at increasing $25(\mathrm{OH})$ $\mathrm{D}$ levels in dialysis patients than oral supplementation and achieves more increase in serum calcium and reduce PTH concentration, however, longer duration of treatment is required to achieve recommended levels of vitamin $\mathrm{D}$ and suppress high PTH levels.

\section{Limitations of the study}

That it is a pilot study of the short-term effect of cholecalciferol supplementation with small sample size. Limitation of assessment calcifications and BMD in this study.

\section{Conflicts of interest}

The authors declare that there is no conflicts of interest.

\section{Ethical issues}

The research conducted in accordance with the tenets of the Declaration of Helsinki. The research ethics committee (assurance No. FWA 000017585) of Ain-Shams university hospital approved this study. Accordingly, written informed consent was taken from all participants before any intervention. This study was part of internal medicine residential thesis of Zeinab Ahmed Mahmoud at this university. The trial protocol was approved in Ain shams university ethical committee with number (FMASU MD 292 2018). Moreover, ethical issues (including plagiarism, data fabrication, double publication) have been completely observed by the authors.

\section{Funding/Support}

No funding was received.

\section{References}

1. Jean G, Souberbielle JC, Chazot C. Vitamin D in chronic kidney disease and dialysis patients. Nutrients. 2017;9:328. doi: 10.3390/nu9040328.

2. Aranow C. Vitamin D and the immune system. J Investig Med. 2011;59:881-6. doi: 10.2310/JIM.0b013e31821b8755.

3. Bhan I, Hewison M, Thadhani R. Dietary vitamin D intake in advanced CKD/ESRD. Semin Dial. 2010;23:407-10. doi: 10.1111/j.1525-139X.2010.00751.x.

4. Holick MF. Vitamin D deficiency. N Engl J Med. 2007; 357:266-81. doi: 10.1056/NEJMra070553.

5. Souberbielle JC, Body JJ, Lappe JM, Plebani M, Shoenfeld Y, Wang TJ, et al. Vitamin D and musculoskeletal health, cardiovascular disease, autoimmunity and cancer: recommendations for clinical practice. Autoimmun Rev. 2010;9:709-15. doi: 10.1016/j.autrev.2010.06.009.

6. Melamed ML, Michos ED, Post W, Astor B. 25-hydroxyvitamin D levels and the risk of mortality in the general population. Arch Intern Med. 2008;168:1629-37. doi: $\quad$ 10.1001/archinte.168.15.1629.

7. Shaffi K, Tighiouart H, Scott T, Lou K, Drew D, Weiner $\mathrm{D}$, et al. Low 25-hydroxyvitamin $\mathrm{D}$ levels and cognitive impairment in hemodialysis patients. Clin J Am Soc Nephrol. 2013;8:979-86. doi: 10.2215/cjn.10651012.

8. Guessous I, McClellan W, Kleinbaum D, Vaccarino V, Zoller O, Theler JM, et al. Comparisons of serum vitamin $\mathrm{D}$ levels, status, and determinants in populations with and without chronic kidney disease not requiring renal dialysis: a 24-hour urine collection population-based study. J Ren Nutr. 2014;24:303-12. doi: 10.1053/j.jrn.2014.04.005.

9. Del Valle E, Negri AL, Aguirre C, Fradinger E, Zanchetta 
JR. Prevalence of $25(\mathrm{OH})$ vitamin D insufficiency and deficiency in chronic kidney disease stage 5 patients on hemodialysis. Hemodial Int. 2007;11:315-21. doi: 10.1111/j.1542-4758.2007.00186.x.

10. Cuppari L, Garcia-Lopes MG. Hypovitaminosis D in chronic kidney disease patients: prevalence and treatment. J Ren Nutr. 2009;19:38-43. doi: 10.1053/j.jrn.2008.10.005.

11. Vaziri ND, Hollander D, Hung EK, Vo M, Dadufalza L. Impaired intestinal absorption of vitamin D3 in azotemic rats. Am J Clin Nutr. 1983;37:403-6. doi: 10.1093/ ajcn/37.3.403.

12. Gunville CF, Mourani PM, Ginde AA. The role of vitamin $\mathrm{D}$ in prevention and treatment of infection. Inflamm Allergy Drug Targets. 2013;12:239-45. doi: 10.2174/18715281113129990046.

13. Al Mheid I, Patel RS, Tangpricha V, Quyyumi AA. Vitamin $\mathrm{D}$ and cardiovascular disease: is the evidence solid? Eur Heart J. 2013;34:3691-8. doi: 10.1093/eurheartj/eht166.

14. Melamed ML, Thadhani RI. Vitamin D therapy in chronic kidney disease and end stage renal disease. Clin J Am Soc Nephrol. 2012;7:358-65. doi: 10.2215/cjn.04040411.

15. Bataille S, Landrier JF, Astier J, Giaime P, Sampol J, Sichez $\mathrm{H}$, et al. The "dose-effect" relationship between 25-hydroxyvitamin D and muscle strength in hemodialysis patients favors a normal threshold of $30 \mathrm{ng} / \mathrm{mL}$ for plasma 25-hydroxyvitamin D. J Ren Nutr. 2016;26:45-52. doi: 10.1053/j.jrn.2015.08.007.

16. Fusaro M, Gallieni M, Rebora P, Rizzo MA, Luise MC, Riva $\mathrm{H}$, et al. Atrial fibrillation and low vitamin D levels are associated with severe vascular calcifications in hemodialysis patients. J Nephrol. 2016;29:419-26. doi: 10.1007/s40620-015-0236-7.

17. Benhamou CL, Souberbielle JC, Cortet B, Fardellone P, Gauvain JB, Thomas T. Vitamin D in adults: GRIO guidelines. Presse Med. 2011;40:673-82. doi: 10.1016/j. lpm.2011.04.001.

18. Binkley N, Ramamurthy R, Krueger D. Low vitamin D status: definition, prevalence, consequences, and correction. Endocrinol Metab Clin North Am. 2010;39:287-301. doi: 10.1016/j.ecl.2010.02.008.

19. Fellay B, Guillod Y, Jorand N, Allemann G, Magnin JL, Descombes E. Accuracy of five 25-hydroxyvitamin D assays as compared to the reference method LC-MS/MS in chronic hemodialysis patients. Swiss Med Wkly. 2012;142:17-8. doi: 10.13140/rg.2.1.2247.6646.

20. Heijboer AC, Blankenstein MA, Kema IP, Buijs MM. Accuracy of 6 routine 25-hydroxyvitamin D assays: influence of vitamin D binding protein concentration. Clin Chem. 2012;58:543-8. doi: 10.1373/clinchem.2011.176545.

21. Eckardt KU, Kasiske BL. Kidney disease: improving global outcomes. Nat Rev Nephrol. 2009;5:650-7. doi: 10.1038/ nrneph.2009.153.

22. Tokmak F, Quack I, Schieren G, Sellin L, Rattensperger D, Holland-Letz T, et al. High-dose cholecalciferol to correct vitamin D deficiency in haemodialysis patients. Nephrol Dial Transplant. 2008;23:4016-20. doi: 10.1093/ndt/gfn367.

23. Jean G, Lafage-Proust MH, Massy ZA, Drüeke TB. [Guidelines for vitamin $\mathrm{D}$ prescription in dialysis patients]. Nephrol Ther. 2009;5:520-32. doi: 10.1016/j. nephro.2009.07.010.

24. Descombes E, Boulat O, Perriard F, Fellay G. Watersoluble vitamin levels in patients undergoing high-flux hemodialysis and receiving long-term oral postdialysis vitamin supplementation. Artif Organs. 2000;24:773-8. doi: 10.1046/j.1525-1594.2000.06553.x.

25. Audran M, Briot K. Critical reappraisal of vitamin D deficiency. Joint Bone Spine. 2010;77:115-9. doi: 10.1016/j. jbspin.2009.12.003.

26. Martineau AR, Jolliffe DA, Hooper RL, Greenberg L, Aloia JF, Bergman P, et al. Vitamin D supplementation to prevent acute respiratory tract infections: systematic review and meta-analysis of individual participant data. BMJ. 2017;356:i6583. doi: 10.1136/bmj.i6583.

27. Sanders KM, Stuart AL, Williamson EJ, Simpson JA, Kotowicz MA, Young D, et al. Annual high-dose oral vitamin $\mathrm{D}$ and falls and fractures in older women: a randomized controlled trial. JAMA. 2010;303:1815-22. doi: 10.1001/jama.2010.594.

28. Bischoff-Ferrari HA, Dawson-Hughes B, Orav EJ, Staehelin HB, Meyer OW, Theiler R, et al. Monthly high-dose vitamin $\mathrm{D}$ treatment for the prevention of functional decline: a randomized clinical trial. JAMA Intern Med. 2016;176:17583. doi: 10.1001/jamainternmed.2015.7148.

29. Nigwekar SU, Bhan I, Thadhani R. Ergocalciferol and cholecalciferol in CKD. Am J Kidney Dis. 2012;60:139-56. doi: $10.1053 /$ j.ajkd.2011.12.035.

30. Heaney RP, Barger-Lux MJ, Dowell MS, Chen TC, Holick MF. Calcium absorptive effects of vitamin D and its major metabolites. J Clin Endocrinol Metab. 1997;82:4111-6. doi: 10.1210/jcem.82.12.4412.

31. Jean G, Terrat JC, Vanel T, Hurot JM, Lorriaux C, Mayor B, et al. Daily oral 25-hydroxycholecalciferol supplementation for vitamin D deficiency in haemodialysis patients: effects on mineral metabolism and bone markers. Nephrol Dial Transplant. 2008;23:3670-6. doi: 10.1093/ndt/gfn339.

32. Bhan I, Dobens D, Tamez H, Deferio JJ, Li YC, Warren HS, et al. Nutritional vitamin D supplementation in dialysis: a randomized trial. Clin J Am Soc Nephrol. 2015;10:611-9. doi: $10.2215 /$ cjn. 06910714 .

33. Tripkovic L, Lambert H, Hart K, Smith CP, Bucca G, Penson S, et al. Comparison of vitamin D2 and vitamin D3 supplementation in raising serum 25-hydroxyvitamin D status: a systematic review and meta-analysis. Am J Clin Nutr. 2012;95:1357-64. doi: 10.3945/ajcn.111.031070.

34. Houghton LA, Vieth R. The case against ergocalciferol (vitamin D2) as a vitamin supplement. Am J Clin Nutr. 2006;84:694-7. doi: 10.1093/ajcn/84.4.694.

Copyright $\odot 2022$ The Author(s); Published by Society of Diabetic Nephropathy Prevention. This is an open-access article distributed under the terms of the Creative Commons Attribution License (http://creativecommons.org/licenses/by/4.0), which permits unrestricted use, distribution, and reproduction in any medium, provided the original work is properly cited. 